\title{
Inhibitory effect of hop fractions against Gram-positive multi-resistant bacteria. A pilot study
}

\author{
Katerina Bogdanovaa ${ }^{a}$, Milan Kolara, Katerina Langova ${ }^{a}$, Martin Dusek ${ }^{b}$, Alexandr Mikyska ${ }^{b}$, Vanda Bostikova ${ }^{c}$, Pavel Bostikc, \\ Jana Olsovskab
}

\begin{abstract}
Aim. Our research focused on the antimicrobial effects of purified hop (Humulus lupulus $\mathrm{L}$.) fractions including a-bitter acids (humulones), $\beta$-bitter acids (lupulones) and xanthohumol, and a commercial $\mathrm{CO}_{2}$ hop extract of bitter acids against reference and multi-resistant strains of Gram-positive and Gram-negative bacteria and against selected yeast strains. Methods. In vitro testing of antimicrobial activity was performed according to standard testing protocols (EUCAST). The effects of hop extracts on bacterial/yeast strains at concentrations below MICs were also determined and the antimicrobial potential of hop extracts was compared with selected antibiotics using optical density measurement.

Results. The fractions were effective not only against reference strains of Gram-positive bacteria but, more importantly, against their methicillin- and vancomycin-resistant variants. No antimicrobial effect was detected against Gram-negative bacterial strains. Among the tested substances, xanthohumol was identified as the hop fraction with the most potent antimicrobial properties. It was also found that hop substances exerted their antimicrobial effects at concentrations considerably lower than the determined MICs, with the strongest effect in case of a-bitter acids in enterococci.

Conclusion. The search for and research of new compounds with antimicrobial properties represents a possible solution to the current global problem of bacterial resistance. Our data suggest a desirable activity of hop fractions against some multi-resistant bacterial strains. Thus, hops might find use as a source of potential antimicrobial agents applicable in both human and veterinary medicine.
\end{abstract}

Key words: humulone, lupulone, xanthohumol, Humulus lupulus L., antimicrobial properties, multi-resistant bacteria

Received: December 1, 2017; Accepted with revision: May 10, 2018; Available online: May 23, 2018

https://doi.org/10.5507/bp.2018.026

${ }^{a}$ Department of Microbiology, Faculty of Medicine and Dentistry, Palacky University Olomouc, Hnevotinska 3, Olomouc, Czech Republic ${ }^{b}$ Research Institute of Brewing and Malting, PLC, Lipova 15, Prague, Czech Republic

'Faculty of Military Health Sciences, University of Defence, Trebesska 1575, Hradec Kralove, Czech Republic

Corresponding author: Katerina Bogdanova, e-mail: katerina.bogdanova@upol.cz

\section{INTRODUCTION}

In the community and particularly in the hospital setting, antibiotics face the growing problem of multi-resistant Gram-negative and Gram-positive bacteria ${ }^{1,2}$. Despite a slight decrease in the percentage of methicillin-resistant Staphylococcus aureus (MRSA), it remains a public health problem in Europe. In 2013, seven out of 30 countries reported MRSA prevalence above 25\% (ref. ${ }^{2}$ ). Moreover, a significant increase of vancomycin-resistant Enterococcus faecium in Europe has been reported ${ }^{3}$.

The development of a novel antibiotic is a lengthy and expensive process with an uncertain outcome whereas the ability of bacteria to develop resistance is unpredictable in its occurrence. Since 2000, only five antibiotics with new mechanisms of action have been approved by the FDA. Years have elapsed since new antibiotics with activity against Gram-negative bacteria, tigecycline in 2005 and recently POL 7080, were developed. The latter antibiotic received the Qualified Infectious Disease Product designation from the FDA in November 2014 (ref. ${ }^{4}$ ).

The current mainly synthetic approaches to create new antimicrobials can be expanded by utilizing compounds of natural origin. The novel promising antibiotic teixobac- tin was obtained from uncultured soil bacteria ${ }^{5}$. Another source of antimicrobial substances are traditional herbal medicines ${ }^{6}$. Among others, the hop plant (Humulus lupulus L.), with its long history in traditional medicine, has been used in the treatment of many conditions including bacterial infections, and also for its qualities as a preservative $^{7}$. Recent studies describe biological activities of hop metabolites, including their antibacterial, antifungal and antiviral activities and their future therapeutic potential ${ }^{8-11}$. So far, the reported antibacterial activity is mainly against Gram-positive bacteria. Evrendilek described the effect of hop essential oil on pathogenic bacteria such as Yersinia enterocolitica, Salmonella Enteritidis and Salmonella Typhimurium, Proteus mirabilis, Escherichia coli O157:H7 and Klebsiella oxytoca ${ }^{10}$. Recently, the antimicrobial activity of hop derivatives against gut anaerobic bacteria, in particular resistant strains of Clostridium difficile, has been described ${ }^{12}$.

Hop plant extracts were tested for their biological activity against orodental pathogens $\mathbf{s}^{13-16}$. In a study by Yamaguchi et al., bacteria involved in acne vulgaris, that is, Propionibacterium acnes, Staphylococcus epidermidis, Staphylococcus aureus, Streptococcus pyogenes and Kocuria rhizophila, were inhibited by xanthohumol and lupulones. 
Moreover, anticollagenase and antioxidant effects of tested hop components were also demonstrated ${ }^{17}$. Deodorant and antibacterial effects of topically applied supercritical hop extracts were described in another study ${ }^{18}$.

The hop metabolites most commonly described and explored for their multiple biomedical effects are soft resins, $\alpha$-bitter acids ( $\alpha$-acids, humulones) and $\beta$-bitter acids ( $\beta$-acids, lupulones), and prenylflavonoids (Fig. 1), compounds from the large family of polyphenols. Humulones and lupulones consist of three major analogues, humulone, cohumulone, adhumulone and lupulone, colupulone, adlupulone, respectively. The minor analogues are prehumulone, posthumulone and prelupulone, postlupulone, respectively (Fig. 1).

The antimicrobial effect of some hop components has usually been studied on individual or a narrow range of microorganisms without explaining the consequences of their action. Recently, we published a study confirming that hops contain a wide range of compounds with an analogous structure including the prenyl and/or geranyl groups ${ }^{19}$. Based on the fact that these compounds were identified in inhibition zones in Petri dishes, where minced hop cones were applied onto a solid growth medium inoculated with Staphylococcus aureus, they were assumed to be mainly responsible for the antimicrobial properties of hops. We therefore focused on the aforementioned $\alpha$-acids, $\beta$-acids and xanthohumol, which contain one or more prenyl group(s) but the remaining part of the structure is at least similar (see Fig. 1).

Thus, the aims of the present study were the evaluation and comparison of the effectiveness of antimicrobial action of selected hop fractions with the prenyl group(s) on specific bacterial strains including multi-resistant strains involved in nosocomial infections.

\section{MATERIALS AND METHODS}

\section{Hop extracts}

Four hop extracts, including $(a)$ a commercial $\mathrm{CO}_{2}$ hop extract and three highly purified hop extracts con- taining mainly (b) $\alpha$-bitter acids, (c) $\beta$-bitter acids and (d) xanthohumol, were tested and compared for their antimicrobial activity.

The commercial $\mathrm{CO}_{2}$ hop extract $(a)$ commonly used for beer hopping was purchased from Hopsteiner. It is inexpensive, in comparison with the purified preparations (b-d), and easily accessible. It served especially for the initial development of methods used subsequently in the entire study and as a reference for testing the purified preparations $(b-d)$. The commercial $\mathrm{CO}_{2}$ hop extract was a mixture of $\alpha$-bitter acids and $\beta$-bitter acids (see Table 1 ). Along with preparations of $\alpha$-bitter acids and $\beta$-bitter acids, it was analyzed using the EBC 7.7 method; the sample was extracted to diethyl ether and diluted by methanol prior to high-performance liquid chromatography analysis ${ }^{20}$.

Fractions of $\alpha$ - and $\beta$-bitter acids $(b, c)$ (Table 1) were prepared at the Hop Research Institute in Žatec according to a procedure described by Krofta et al. ${ }^{21}$. The EBC 7.7 method ${ }^{20}$ was used for a chromatographic purity evaluation of these extracts at $314 \mathrm{~nm}$; samples of $\alpha$ - and $\beta$-bitter acids were diluted in methanol prior to the analysis. The structures are depicted in Fig. 1.

The xanthohumol fraction $(d)$ (Table 1) was a kind gift of Dr Martin Biendl from the Hopsteiner research laboratory.

\section{Minimum inhibitory concentration and minimum bacteri- cidal concentration of hop fractions}

The in vitro testing of antimicrobial activity was performed according to standard testing protocols (European Committee on Antimicrobial Susceptibility Testing, EUCAST) and minimum inhibitory concentration (MIC) was determined as the lowest concentration of the tested substance that visibly inhibited the growth of the bacterial strain ${ }^{22}$.

Four different hop components were tested: $\alpha$-bitter acids, $\beta$-bitter acids, xanthohumol and the commercial $\mathrm{CO}_{2}$ hop extract of bitter acids. The dried hop fractions and extract were appropriately stored and, before analysis, reconstituted in a fresh culture medium to prepare stock solutions. Fresh batches of tested samples were
A<smiles>[R]C(=O)C1=C(O)C(CC=C(C)C)=C(O)C(O)(CC=C(C)C)C1=O</smiles>

B<smiles>[R]C(=O)C1=C(O)C(CC=C(C)C)=C(O)C(CC=C(C)C)(CC=C(C)C)C1=O</smiles>

C<smiles>COc1cc(O)c(CC=C(C)C)c(O)c1C(=O)/C=C/c1ccc(O)cc1</smiles>

Fig. 1. Structural formulae of tested hop components.

(A) $\alpha$-bitter acids (humulones): humulone $R=\mathrm{CH}_{2} \mathrm{CH}\left(\mathrm{CH}_{3}\right)_{2}$, cohumulone $R=\mathrm{CH}\left(\mathrm{CH}_{3}\right)_{2}$, adhumulone $R=\mathrm{CH}\left(\mathrm{CH}_{3}\right) \mathrm{CH}_{2} \mathrm{CH}_{3}, \mathrm{prehumulone}$ $R=\mathrm{CH}_{2} \mathrm{CH}_{2} \mathrm{CH}\left(\mathrm{CH}_{3}\right)_{2}$, posthumulone $R=\mathrm{CH}_{2} \mathrm{CH}_{3} ;$ (B) - $\beta$-bitter acids (lupulones): lupulone $R=\mathrm{CH}_{2} \mathrm{CH}\left(\mathrm{CH}_{3}\right)_{2}$, colupulone $R=\mathrm{CH}\left(\mathrm{CH}_{3}\right)_{2}$, adlupulone $R=\mathrm{CH}\left(\mathrm{CH}_{3}\right) \mathrm{CH}_{2} \mathrm{CH}_{3}$, prelupulone $R=\mathrm{CH}_{2} \mathrm{CH}_{2} \mathrm{CH}\left(\mathrm{CH}_{3}\right)_{2}$, postlupulone $R=\mathrm{CH}_{2} \mathrm{CH}_{3}$ and (C) xanthohumol. 
Table 1. The composition of tested hop fractions.

\begin{tabular}{llcl}
\hline Fraction & $\begin{array}{c}\text { Content of major } \\
\text { components }(\%)\end{array}$ & Content of minor components (\%) \\
\hline 1 & $\mathrm{CO}_{2}$ & $46.7 \alpha$-acids & $26.5 \beta$-acids, 26.5 non-specific soft resins \\
2 & $\alpha$-acids & 83.2 & $0.7 \beta$-acids, 15.9 non-specific soft resins \\
3 & $\beta$-acids & 97.3 & $<0.1 \alpha$-acids, 0.3 soft resins \\
4 & xanthohumol & 90.0 & 5.0 desmethylxanthohumol, 2.0 xanthohumol C, 3.0 other prenylflavonoids \\
\hline
\end{tabular}

prepared for each experiment. Antimicrobial effects of isolated hop fractions were tested on the following reference strains: Staphylococcus aureus ATCC 25923, Enterococcus faecalis ATCC 29212, Escherichia coli ATCC 25922 and Pseudomonas aeruginosa ATCC 27853. The resistant bacterial strains included methicillin-resistant Staphylococcus aureus 4591 (MRSA), fluoroquinoloneresistant Staphylococcus haemolyticus 16568 (FQR), vancomycin-resistant Enterococcus faecium VanA 419/Ana (VRE), fluoroquinolone-resistant Escherichia coli 16702 (FQR) and fluoroquinolone-resistant Pseudomonas aeruginosa 16575 (FQR). The yeast strains used in the evaluation included Candida albicans, Candida krusei, Candida parapsilosis and Candida tropicalis, all from the culture collection of the Department of Microbiology (Faculty of Medicine and Dentistry, Palacky University Olomouc).

ITEST Kryobanka B (ITEST plus) was used for storage of bacterial strains at $-80^{\circ} \mathrm{C}$. The Phoenix automated system (Becton Dickinson) and MALDI-TOF Biotyper system (Bruker Daltonics) were used for the identification of individual non-reference bacterial strains.

Bacteria and yeasts were grown at $35^{\circ} \mathrm{C}$ for $24 \mathrm{~h}$ on blood agar (bacteria) or Sabouraud agar (yeasts) (TRIOS), and microbial suspensions $\left(10^{6} \mathrm{CFU} / \mathrm{mL}\right)$ were prepared in $2 \mathrm{~mL}$ of saline buffer (TRIOS). Stock solutions of hop fractions were diluted in culture broth (BHI broth, Brain-Heart Infusion, HiMedia) in microtiter plates using a twofold dilution system within a final concentration range of $0.1-1000 \mathrm{mg} / \mathrm{L}$. The plates were then inoculated with microbial suspensions so that the final bacterial concentration was $10^{6} \mathrm{CFU} / \mathrm{mL}$ per well. Microplate wells inoculated with the tested bacterial strain without hop fractions were used as positive controls and wells containing tested hop fractions without bacterial strains were used as negative controls. The plates were incubated at $35^{\circ} \mathrm{C}$ for 24 (bacteria) or 48 (yeasts) h and MICs were determined. To measure the minimum bactericidal concentration (MBC), the content of the wells with visibly inhibited growth was inoculated onto blood agar (bacteria) or Sabouraud agar (yeasts) and incubated at 35 ${ }^{\circ} \mathrm{C}$ for additional 24 or $48 \mathrm{~h}$, respectively. Negative growth of microbial colonies determined the MBCs.

\section{Evaluation of the effect of sub-inhibitory concentrations of hop extracts on bacterial/yeast growth}

Microplates with phytoextracts exponentially diluted in culture broth (BHI) were inoculated with one tested bacterial/yeast strain at a time as described above and incubated at $35^{\circ} \mathrm{C}$ for 24 (bacteria) or 48 (yeasts) h. The concentrations of tested hop extracts ranged from MIC to $\mathrm{MIC} / 100$. MIC values were determined in the previous step (see above). Also, microplates with the culture medium only (BHI) were inoculated with bacterial/yeast strains to be used as controls. This was followed by optical density measurement at $630 \mathrm{~nm}$ using the BIO-TEK ELx808 spectrophotometer. Values with considerably decreased optical density in comparison to controls were used to plot graphs and for statistical evaluation.

\section{Comparison of antimicrobial effects of highly purified hop extracts with selected antibiotics in Gram-positive bacteria}

The MICs of selected antibiotics were determined using a broth microdilution method as described by the EUCAST (ref. ${ }^{22}$ ). The antibiotics included penicillin (Biotika), chloramphenicol (Sigma-Aldrich), tetracycline (Sigma-Aldrich), erythromycin (Serva), clindamycin (Pfeizer), teicoplanin (Sanofi) and vancomycin (Mylan). The plates with diluted antibiotics were then inoculated with microbial suspensions of the following Gram-positive bacterial strains: Staphylococcus aureus ATCC 25923, Enterococcus faecalis ATCC 29212, Staphylococcus aureus 4591 (MRSA), Staphylococcus haemolyticus 16568 (FQR) and Enterococcus faecium VanA 419/Ana (VRE).

Based on MIC values determined in previous experiments against Gram-positive bacteria, tested fractions of $\alpha$-bitter acids, $\beta$-bitter acids and xanthohumol were diluted in $1 \mathrm{~mL}$ of $\mathrm{BHI}$ in test tubes so that a concentration of 1/10 of the MIC was achieved. Two selected antibiotics, chloramphenicol (Sigma Aldrich) and teicoplanin (Sanofi), were prepared for testing in the same way. Test tubes with prepared solutions of hop fractions and antibiotics were inoculated with the above Gram-positive bacterial strains. Also, as control samples, test tubes with BHI only were inoculated with the bacterial strains. Inoculated test tubes (the concentration of bacterial suspension was $10^{6} \mathrm{CFU} / \mathrm{mL}$ ) were incubated at $35^{\circ} \mathrm{C}$ for $24 \mathrm{~h}$. After incubation, the test tubes were shaken thoroughly and $100 \mu \mathrm{L}$ of the bacterial suspension was transferred into microtiter plate wells and optical density $(630 \mathrm{~nm})$ was measured (BIO-TEK ELx808).

\section{Statistical evaluation}

All tests were repeated four times, each time in duplicates, always with freshly prepared phytoextracts and with new bacterial preparations. The IBM SPSS Statistics 23 software was used for all statistical analyses. The comparison among tested hop extracts and between reference and resistant bacterial strains was performed with the Kruskal-Wallis test with post hoc multiple comparisons 
Table 2. Antimicrobial activities (MICs and MBCs) of $\alpha$-bitter acids (a mixture of homologues), $\beta$-bitter acids (a mixture of homologues), xanthohumol and the commercial $\mathrm{CO}_{2}$ hops extract of bitter acids (content of $\alpha$ - and $\beta$-bitter acids $47 \%$ and $27 \%$, respectively) against reference bacterial strains, resistant bacterial strains and yeast strains determined by microdilution broth assay (MIC determination) followed by growth on solid media (MBC determination).

\begin{tabular}{|c|c|c|c|c|}
\hline & \multicolumn{4}{|c|}{ Hop fraction $(\mathrm{mg} / \mathrm{L})$} \\
\hline & $\alpha$-bitter acids & $\beta$-bitter acids & Xanthohumol & $\begin{array}{l}\text { Commercial } \mathrm{CO}_{2} \text { hops } \\
\text { extract of bitter acids }\end{array}$ \\
\hline Staphylococcus aureus ATCC 25923 & $30[30]$ & $0.5[2]$ & $4[4]$ & $7.5[125]$ \\
\hline Enterococcus faecalis ATCC 29212 & $60[125]$ & $15[30]$ & $7.5[\mathrm{n}]$ & $60[\mathrm{n}]$ \\
\hline Escherichia coli ATCC 25922 & $\mathrm{n}[\mathrm{n}]$ & $\mathrm{n}[\mathrm{n}]$ & $\mathrm{n}[\mathrm{n}]$ & $\mathrm{n}[\mathrm{n}]$ \\
\hline Pseudomonas aeruginosa ATCC 27853 & $\mathrm{n}[\mathrm{n}]$ & $\mathrm{n}[\mathrm{n}]$ & $\mathrm{n}[\mathrm{n}]$ & $\mathrm{n}[\mathrm{n}]$ \\
\hline Staphylococcus aureus MRSA & $60[250]$ & $1[125]$ & $4[4]$ & $7.5[250]$ \\
\hline Enterococcus faecium VanA VRE & $60[\mathrm{n}]$ & $15[n]$ & $7.5[\mathrm{n}]$ & $30[\mathrm{n}]$ \\
\hline Staphylococcus haemolyticus FQR & $30[60]$ & $1[1]$ & $7.5[7.5]$ & $15[15]$ \\
\hline Escherichia coli FQR & $\mathrm{n}[\mathrm{n}]$ & $\mathrm{n}[\mathrm{n}]$ & $\mathrm{n}[\mathrm{n}]$ & $\mathrm{n}[\mathrm{n}]$ \\
\hline Pseudomonas aeruginosa $\mathrm{FQR}$ & $\mathrm{n}[\mathrm{n}]$ & $\mathrm{n}[\mathrm{n}]$ & $\mathrm{n}[\mathrm{n}]$ & $\mathrm{n}[\mathrm{n}]$ \\
\hline Candida albicans & $250[250]$ & $500[500]$ & $60[60]$ & $250[250]$ \\
\hline Candida krusei & $250[250]$ & $500[500]$ & $60[60]$ & $250[250]$ \\
\hline Candida tropicalis & 1000 [1000] & $\mathrm{n}[\mathrm{n}]$ & $30[30]$ & 1000 [1000] \\
\hline Candida parapsilosis & $500[500]$ & $1000[1000]$ & $7.5[7.5]$ & $500[500]$ \\
\hline
\end{tabular}

MIC is determined as the lowest concentration of the tested compound that visibly inhibits bacterial growth - values presented without brackets. $\mathrm{MBC}$ is determined as the lowest concentration of the tested compound that kills bacteria - values presented within brackets.

$\mathrm{n}$ depicts values above $1000 \mathrm{mg} / \mathrm{L}$ meaning positive growth of microorganisms even in the highest tested concentrations of hop fractions.

comparing three or more groups. The Bonferroni correction was used to correct $P$-values. The Mann-Whitney U-test compared two groups. Differences were considered significant at $\alpha=0.05$. The Wilcoxon test for paired data was used to assess the decrease of bacterial growth in the presence of sub-inhibitory concentrations of hop extracts. The Bonferroni correction was used for multiple comparisons of antimicrobial effects of hop extracts with selected antibiotics.

\section{RESULTS AND DISCUSSION}

To evaluate potential antimicrobial effects of the hopderived fractions, the MIC and MBC were determined for each strain of Gram-negative and Gram-positive bacteria and yeasts (Table 2).

The values for hop fractions against Gram-negative bacteria were above $1000 \mathrm{mg} / \mathrm{L}$, pointing to positive growth of the tested bacteria even at the highest tested concentration. These data are consistent with most previously published studies on antibacterial effects of hop extracts $^{11,23,24}$. Only very few studies have shown some antibacterial effect of hop compounds against Gramnegative bacteria. Evrendilek summarized the effects of essential oils from various plants including hops on common pathogenic bacteria. A disk diffusion assay of six Gram-negative bacteria showed that Yersinia enterocolitica was inhibited the most by compounds from bay leaves, Izmir oregano and hops (a halo diameter for hops of $37.1 \pm 3.7 \mathrm{~mm}$ ). Antibacterial effects of hop essential oils against the rest of Gram-negative bacteria tested were weak, with halo diameters ranging from $11.6 \pm 4.4 \mathrm{~mm}$ in Salmonella Enteritidis to $6.0 \pm 0.1 \mathrm{~mm}$ in Proteus mirabilis and Klebsiella oxytoca ${ }^{10}$. Other studies described some activity of hop extracts against Helicobacter pylori ${ }^{25,26}$ and a strong activity of a homogenate of green hops against Helicobacter pylori ${ }^{27}$.

In contrast, the hop fractions exhibited antimicrobial activities against Gram-positive bacteria, with both the commercial hop extract and each of the purified extract showing some levels of antimicrobial activity.

The commercial hop extract (a mixture of $\alpha$ - and $\beta$-bitter acids) was clearly most effective against both the reference and resistant strains of Staphylococcus aureus (MIC=7.5 mg/L). The effectiveness against Staphylococcus haemolyticus was slightly lower, but still remarkable (MIC=15 mg/L). The lowest effectiveness of this extract against Gram-positive bacteria was detected in the reference strain Enterococcus faecalis and resistant strain Enterococcus faecium VRE (MIC=60 and $30 \mathrm{mg} / \mathrm{L}$, respectively).

We subsequently investigated the effectiveness of $\alpha$ - and $\beta$-bitter acids as part of the commercial extract. The MICs of $\alpha$-bitter acids ranged from $30 \mathrm{mg} / \mathrm{L}$ for the reference strain of Staphylococcus aureus and resistant strain of Staphylococcus haemolyticus (FQR) to 60 $\mathrm{mg} / \mathrm{L}$ for the resistant strains of Staphylococcus aureus (MRSA), Enterococcus faecalis and Enterococcus faecium (VRE). In staphylococci, the MICs of the commercial $\mathrm{CO}_{2}$ hop extract were clearly lower than the MICs of $\alpha$-bitter acids and these differences were highly signifi- 


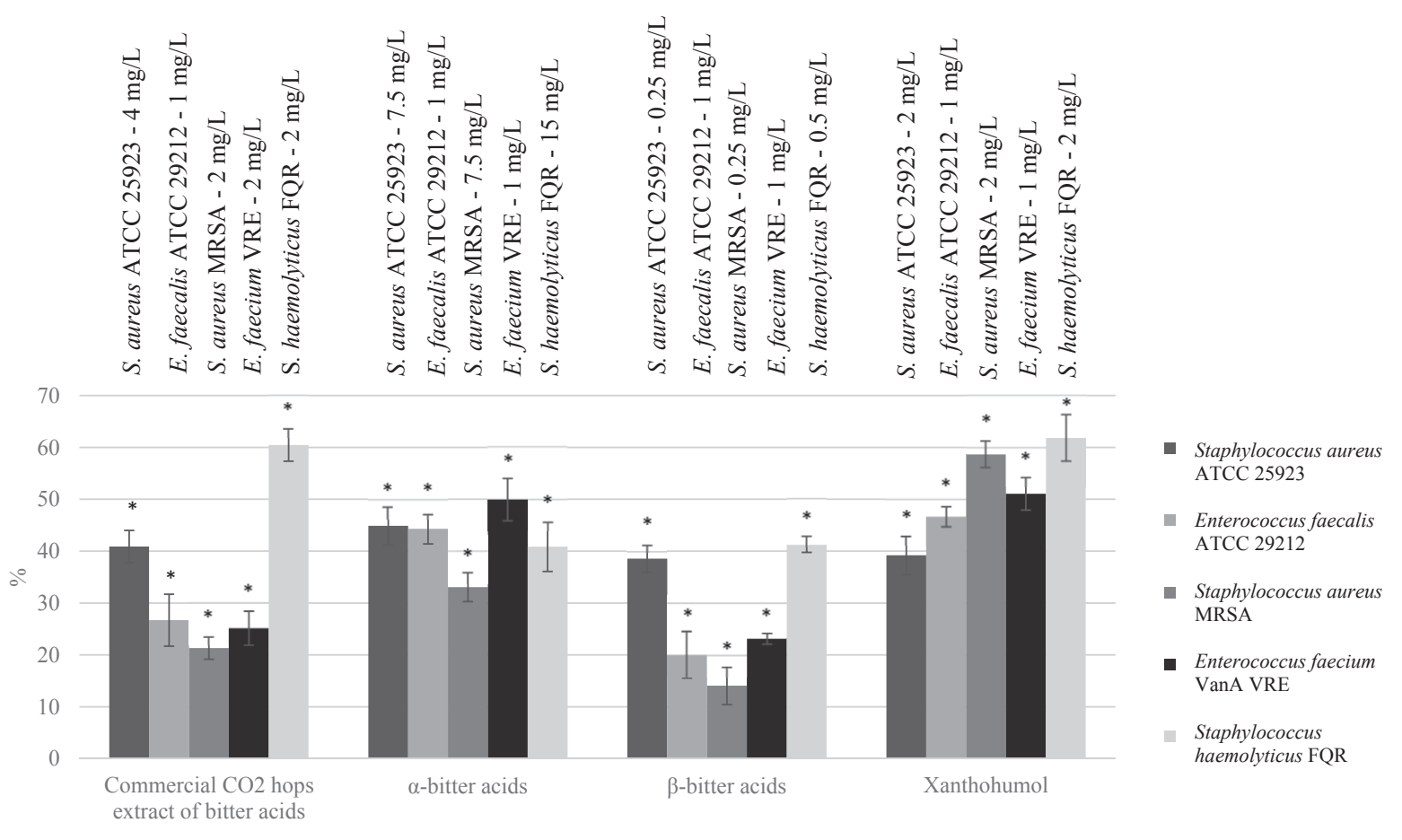

Fig. 2. Bacterial growth reduction in the presence of sub-inhibitory concentration of hop fractions.

Results are presented as reduction percentages in comparison to controls (100\%). Error bars depict the standard deviations. Above every column, the concentration of the hop fraction that caused significant reduction in bacterial growth is shown. Values significantly lower than those obtained for growth control are marked with asterisks: * $P<0.05$.

cant: Staphylococcus aureus $(P=0.0005)$; Staphylococcus aureus MRSA $(P=0.0003)$ and Staphylococcus haemolyticus FQR $(P=0.0006)$.

These data suggest that the main antimicrobial effect of the commercial extract is exerted by $\beta$-bitter acids. Indeed, in all tested samples, $\beta$-bitter acids clearly showed MIC values lower than those obtained using the commercial extract. Similar to the commercial extract, however, the lowest MICs were detected against both the reference and resistant strains of staphylococci $(0.5 \mathrm{mg} / \mathrm{L}$ and $1 \mathrm{mg} / \mathrm{L}$, respectively). In both tested strains of enterococci, the MICs were identical $(15 \mathrm{mg} / \mathrm{L})$.

Furthermore, when the MICs of $\alpha$ - and $\beta$-bitter acids were compared, the latter were significantly lower. The differences for all tested staphylococci were highly significant at $P=0.0003$. Similarly, the significance values of differences in tested enterococci were $P=0.002$ and 0.0005 for Enterococcus faecalis and Enterococcus faecium, respectively. Similarly stronger antibacterial effects of $\beta$-bitter acids (lupulones) compared to $\alpha$-bitter acids (humulones) were shown by others ${ }^{9,17,28}$.

In addition, strong antibiotic effects against Grampositive bacteria were detected for xanthohumol. The MIC values were $4 \mathrm{mg} / \mathrm{L}$ for both tested staphylococci and $7.5 \mathrm{mg} / \mathrm{L}$ for both tested enterococci, regardless of the strains used. In case of Staphylococcus haemolyticus (FQR), the MIC value reached $7.5 \mathrm{mg} / \mathrm{L}$.

Statistical analysis showed that xanthohumol exhibited significantly better antibacterial properties against Gram-positive bacteria than both the commercial extract and $\alpha$-bitter acids. Thus, MICs of xanthohumol were sig- nificantly lower than those of $\alpha$-bitter acids in all tested Gram-positive strains at $P<0.0001$. For the tested strains of enterococci, the MICs of xanthohumol were significantly lower than those of the commercial hop extract at a similar level of significance $(P<0.0001)$. Conversely, the MICs of xanthohumol were significantly higher than those of $\beta$-bitter acids for all tested staphylococci: Staphylococcus aureus $(P=0.003)$; Staphylococcus aureus MRSA $(P=0.033)$ and Staphylococcus haemolyticus FQR $(P<0.0001)$.

Of interest is the fact that there were no significant differences in MICs of identical extracts between resistant and reference strains of staphylococci and enterococci.

As reported earlier, hops bitter acids, in particular humulones ( $\alpha$-bitter acids) more than lupulones ( $\beta$-bitter acids), possess antifungal properties. Together with xanthohumol, antifungal activity was reported mainly against Trichophyton spp., but these extracts were practically inactive against Candida albicans (MIC>200 mg/L) (ref. ${ }^{29,30}$ ). Four pathogenic yeast strains were tested in the present study: Candida albicans, Candida krusei, Candida tropicalis and Candida parapsilosis (Table 2). Some antifungal activity was detected in all tested hop extracts, with MICs of $\alpha$-bitter acids, $\beta$-bitter acids and the commercial extract of bitter acids ranging from $1000 \mathrm{mg} / \mathrm{L}$ to 250 $\mathrm{mg} / \mathrm{L}$ in all tested yeast strains. A more profound effect was detected with xanthohumol, with MIC values of 60 $\mathrm{mg} / \mathrm{L}$ in Candida albicans and Candida krusei, $30 \mathrm{mg} / \mathrm{L}$ in Candida tropicalis and $7.5 \mathrm{mg} / \mathrm{L}$ in Candida parapsilosis. However, the antimicrobial properties were considerably lower when compared to those observed against Gram- 
Table 3. Antimicrobial susceptibility testing.

\begin{tabular}{lccccccc}
\hline & \multicolumn{5}{c}{ MICs of antimicrobial agents (mg/L) with interpretation according to } \\
\cline { 2 - 7 } & PEN & CMP & TET & ERY & CLI & TEI & VAN \\
\hline Breakpoint mg/L & 0.125 & $8^{\mathrm{s}} / 4^{\mathrm{e}}$ & $1^{\mathrm{s}} / 2^{\mathrm{e}}$ & $1^{\mathrm{s}} / 0.25^{\mathrm{e}}$ & $0.25^{\mathrm{s}} / 0.5^{\mathrm{e}}$ & $4^{\mathrm{s} *} / 2^{\mathrm{s} * *} / 2^{\mathrm{e}}$ & $4^{\mathrm{s} *} / 2^{\mathrm{s} * *} / 4^{\mathrm{e}}$ \\
Staphylococcus aureus ATCC 25923 & $0.25[\mathrm{R}]$ & $2[\mathrm{~S}]$ & $<0.1[\mathrm{~S}]$ & $0.2[\mathrm{~S}]$ & $0.1[\mathrm{~S}]$ & $0.1[\mathrm{~S}]$ & $<0.5[\mathrm{~S}]$ \\
Enterococcus faecalis ATCC 29212 & $8[\mathrm{R}]$ & $2[\mathrm{~S}]$ & $16[\mathrm{R}]$ & $2[\mathrm{R}]$ & $>16[\mathrm{R}]$ & $0.2[\mathrm{~S}]$ & $1[\mathrm{~S}]$ \\
Staphylococcus aureus MRSA & $>8[\mathrm{R}]$ & $4[\mathrm{~S}]$ & $<0.1[\mathrm{~S}]$ & $>4[\mathrm{R}]$ & $>4[\mathrm{R}]$ & $0.5[\mathrm{~S}]$ & $<0.5[\mathrm{~S}]$ \\
Enterococcus faecium VanA VRE & $>8[\mathrm{R}]$ & $2[\mathrm{~S}]$ & $>32[\mathrm{R}]$ & $>4[\mathrm{R}]$ & $>16[\mathrm{R}]$ & $4[\mathrm{R}]$ & $16[\mathrm{R}]$ \\
Staphylococcus haemolyticus FQR & $>8[\mathrm{R}]$ & $4[\mathrm{~S}]$ & $<0.1[\mathrm{~S}]$ & $>4[\mathrm{R}]$ & $>4[\mathrm{R}]$ & $0.5[\mathrm{~S}]$ & $<0.5[\mathrm{~S}]$ \\
\hline
\end{tabular}

PEN, penicillin; CMP, chloramphenicol; TET, tetracycline; ERY, erythromycin; CLI, clindamycin; TEI, teicoplanin; VAN, vancomycin; S, sus-

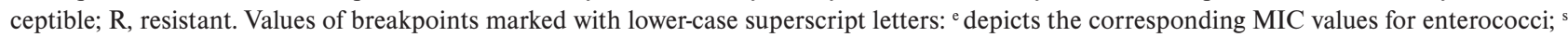
depicts the corresponding MIC values for staphylococci. Values of breakpoints marked with asterisks: * depicts the corresponding MIC values for coagulase-negative staphylococci; ** depicts the corresponding MIC for Staphylococcus aureus.

positive bacteria (Table 2). The MIC values of xanthohumol were significantly lower than MICs of all other tested fractions against all tested yeast strains $(P<0.0005)$, with the exception of Candida tropicalis. In this strain, MICs of xanthohumol were significantly lower than the MICs of the commercial extract $(P=0.002)$ and $\alpha$-bitter acids $(P=0.007)$.

Similar to data reported by Mizobuchi (in case of Trichophyton spp.) (ref. ${ }^{30}$ ), we detected slightly stronger antifungal effects of lupulones ( $\beta$-bitter acids) compared to humulones ( $\alpha$-bitter acids). The difference represented only one dilution step but according to the statistical analysis, it was deemed as significant for Candida albicans $(P=0.026)$ and Candida parapsilosis $(P<0.0005)$. A similar trend was observed for other yeast strains, however, it was not statistically significant $(P=0.053)$. The discordance in hop antifungal activities against yeasts (Candida albicans) in our and Mizobuchi's study may probably be explained by differences in the methods of antimicrobial activity determination.

To determine whether hop extracts at concentrations below MICs affected bacterial growth, optical density of culture broth inoculated with bacterial and yeast strains after incubation with sub-inhibitory concentrations of phytoextracts was evaluated (Fig. 2 and 3). Inhibited proliferation caused by concentrations of hop extracts lower than MICs was detected in all tested Gram-positive bacteria and yeasts. The most prominent effects were observed for Enterococcus faecalis ATCC 29212 and Enterococcus faecium VanA 419/Ana (VRE). In this case, $\alpha$-bitter acids

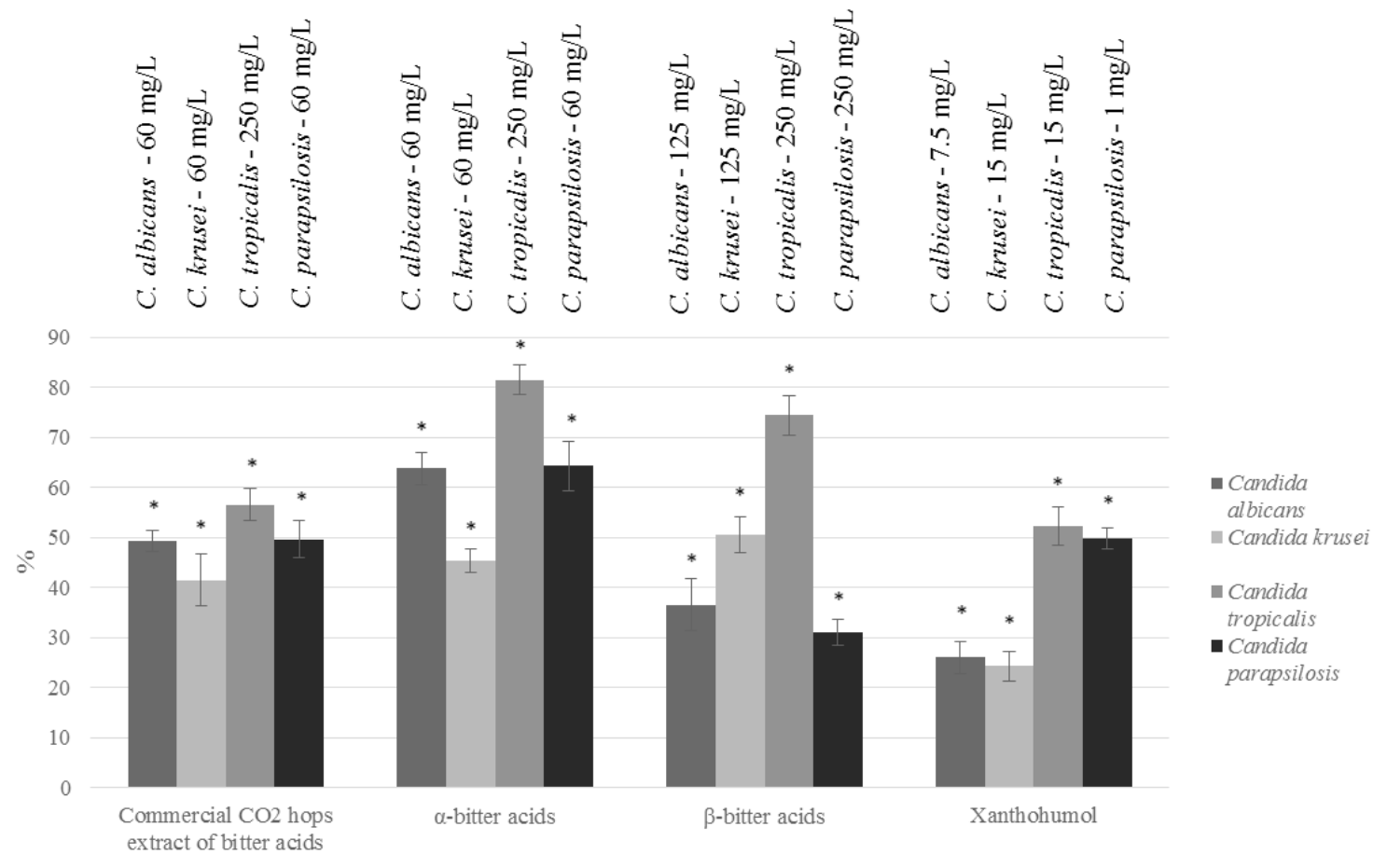

Fig. 3. Yeast growth reduction in the presence of sub-inhibitory concentration of hop fractions.

Results are presented as reduction percentages in comparison to controls (100\%). Error bars depict the standard deviations. Above every column, the concentration of the hop fraction that caused significant reduction in bacterial growth is shown. Values significantly lower than those obtained for growth control are marked with asterisks: * $P<0.05$. 


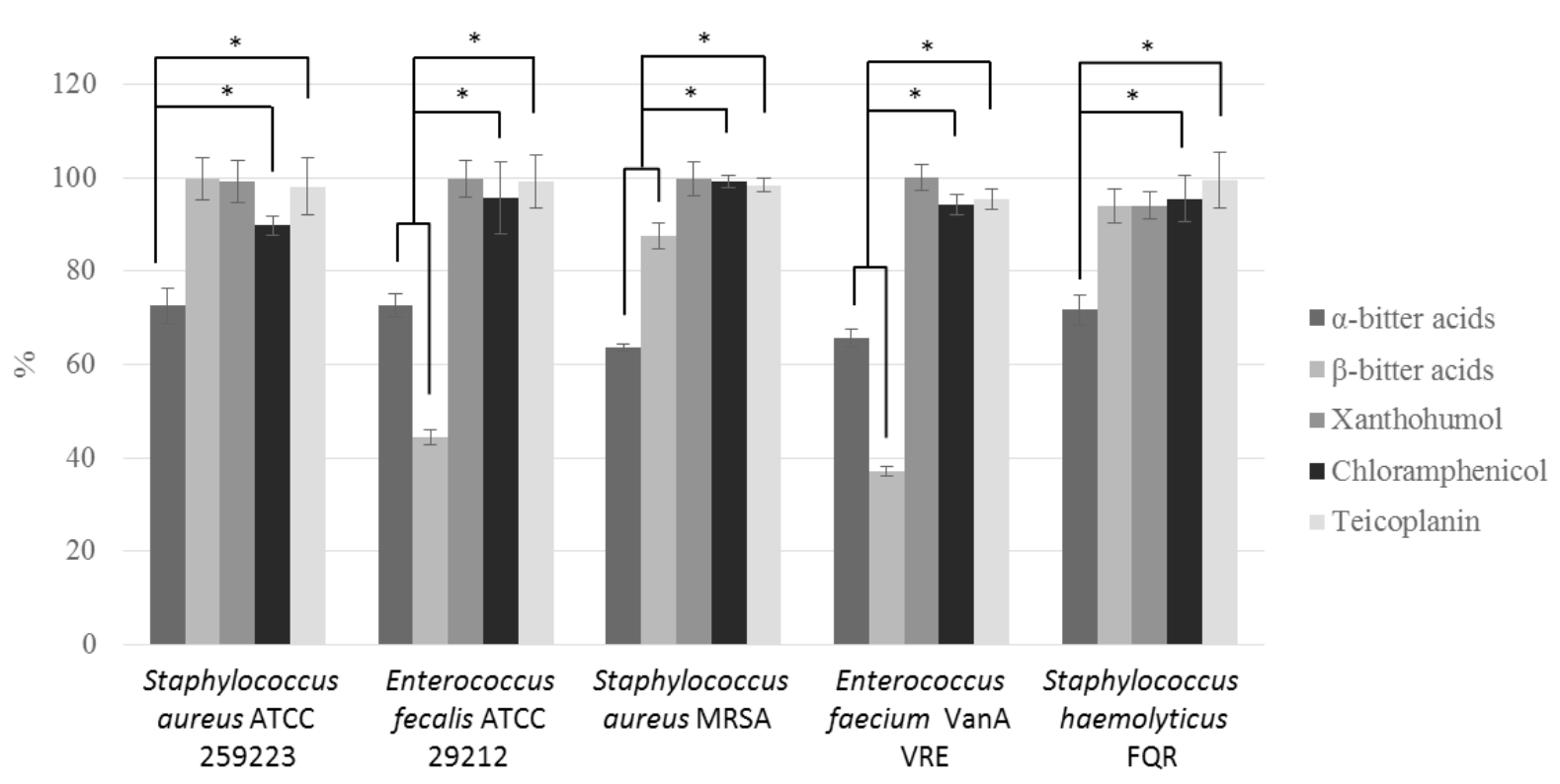

Fig. 4. Reduced growth of Gram-positive bacteria in the presence of $1 / 10$ of the MICs of hop fractions: $\alpha$-bitter acids (a mixture of homologues), $\beta$-bitter acids (a mixture of homologues) and xanthohumol and in the presence of 1/10 of the MICs of two antibiotics: chloramphenicol and teicoplanin.

Results are presented as reduction percentages in comparison to controls (100\%). Error bars depict the standard deviations. Values significantly lower than those obtained for tested antibiotics (chloramphenicol and teicoplanin) are marked with asterisks: ${ }^{*} P<0.05$.

were able to suppress the growth at concentrations 60 times lower than the MICs (Fig. 2). Similar, yet smaller, effects were observed with $\beta$-bitter acids and the commercial extract (Fig. 2). For the remaining strains of tested bacteria and yeasts, the ability of hop extracts to impair their growth ranged from 2- to 8-fold dilutions below MICs (Fig. 2).

Because the commercial hop extract contained a mixture of bitter acids, we decided to use only purified hop extracts for better comparison of their antimicrobial effects with those of selected antibiotics. This test was performed on Gram-positive bacteria only as we obtained the best results with them as tests subjects. We first tested Gram-positive bacteria against a group of 7 antibiotics (Table 3) and selected two antibiotics - chloramphenicol and teicoplanin for further testing. The results are summarized in Fig. 4. To better compare antimicrobial effects, 1/10 of MICs of the tested phytoextracts and antibiotics was used. $\alpha$-bitter acids caused considerable inhibition of bacterial growth in all Gram-positive bacterial strains. The reduction in bacterial numbers was even more pronounced in case of $\beta$-bitter acids, but only in enterococci. On the other hand, this effect was the same in both reference and resistant strains. Almost no antibacterial effect was detected in case of 1/10 of MICs of chloramphenicol and teicoplanin.

The hops matrix has antibacterial properties due to a wide range of biologically active molecules. In our experiments, we were able to compare antimicrobial properties of three main components of the hops matrix. Comparison of antimicrobial activity, expressed as MICs, of the mixture of $\alpha$-bitter acid components and the mixture of $\beta$-bitter acid components clearly shoved approximately one hundred times higher antimicrobial activity of $\beta$-bitter acids for Staphylococcus aureus and Enterococcus faecalis (see Table 2). Both groups of fractions have an identical backbone structure (3,5-dihydroxy-2,4-cyclohexadien1-one) and differ in the substitution of the C6 atom of the ring where the hydroxyl group in $\alpha$-bitter acids is replaced by a third prenyl group in $\beta$-bitter acids (see Fig. $1 \mathrm{~A}$ and 1B). Thus, the stronger biological activity appears to be caused by one pair of prenyl functional groups bound to one $\mathrm{C}$ atom. The antimicrobial activity of xanthohumol with a chalcone backbone (see Fig. 1C) is at least comparable to the activity of $\beta$-bitter acids. The commercial hop extract, composed of $47 \%$ of $\alpha$-bitter acids and $27 \%$ of $\beta$-bitter acids, also shoved stronger antimicrobial activity in comparison to the stand-alone $\alpha$-bitter acids. These data identified the group of fractions mainly responsible for antimicrobial activity of hops. We confirmed the well-known fact that $\alpha$-bitter acids have biological activity but this effect is connected with their high amounts in hop plants rather than with some remarkable antimicrobial activity.

\section{CONCLUSION}

Our study has shown that hop components exhibit very good antibacterial properties in vitro not only against reference strains of Gram-positive bacteria but, more importantly, against their resistant variants such as MRSA or VRE. Alone or in combination with other antimicrobial agents, the hop components can provide a readily available tool to be used for the treatment of infections, especially those caused by Gram-positive bacteria, including multi-resistant bacterial strains and, if confirmed by in vitro and clinical tests, represent non-toxic alternatives for use in nosocomial and other infections. 
Acknowledgement: We would like to thank Dr Karel Krofta from the Hop Research Institute and Dr Martin Biendl from the Hopsteiner for providing the hop preparations. The work was supported by Czech Science Foundation GACR No. 14-10233S and IGA_LF_2018_019.

Author contributions: KB, MK: manuscript writing, data analysis, manuscript revision; KB: literature search, corresponding author MK: final approval; KL: statistical analysis; MD: data analysis; AM: selection and obtaining of hop compounds, consultancy in hop chemistry; VB, PB: manuscript preparation and review; JO: literature search, manuscript management, final approval.

Conflict of interest statement: None declared

\section{REFERENCES}

1. European Centre for Disease Prevention and Control (ECDC) Antimicrobial resistance surveillance in Europe 2014. Annual Report of the European Antimicrobial Resistance Surveillance Network (EARS-Net). ECDC 2015, Stockholm. doi: 10.2900/23549

2. European Centre for Disease Prevention and Control (ECDC). The bacterial challenge: time to react. Stockholm: ECDC 2009. doi: $10.2900 / 2518$

3. Boucher HW, Talbot GH, Benjamin Jr. DK, Bradley J, Guidos RJ, Jones RN, Murray BE, Bonomo RA, Gilbert D. 10 × '20 Progress Development of new drugs active against gram-negative bacilli: An update from the Infectious Diseases Society of America. Clin Infect Dis 2013;56(12):1685-94

4. Bettiol E, Harbarth S. Development of new antibiotics: taking off finally? Swiss Med Wkly [serial on the Internet]. 2015 July [cited 2017 Dec 1]; 145:w14167:[about 9 p.].

5. Ling LL, Schneider T, Peoples AJ, Spoering AL, Engels I, Conlon BP, Mueller A, Schäberle TF, Hughes DE, Epstein S, Jones M, Lazarides L, Steadman VA, Cohen DR, Felix CR, Fetterman KA, Millett WP, Nitti AG, Zullo AM, Chen C, Lewis K. A new antibiotic kills pathogens without detectable resistance. Nature 2015;517(7535):455-9.

6. Rios JL, M. Recio. Medicinal plants and antimicrobial activity. J Ethnopharmacol 2005;100(1-2):80-4.

7. Zanoli P, Zavatti M. Pharmacognostic and pharmacological profile of Humulus lupulus L. J Ethnopharmacol 2008;166(3):383-96.

8. Olsovska J, Bostikova V, Dusek M, Jandovska V, Bogdanova K, Cermak P, Bostik P, Mikyska A, Kolar M. Humulus lupulus L. (hops) - A valuable source of compounds with bioactive effects for future therapies. Mi Med Sci Lett (Voj Zdrav Listy) 2016;85(1):19-30.

9. Gerhäuser C. Broad spectrum antiinfective potential of xanthohumol from hop (Humulus lupulus L.) in comparison with activities of other hop constituents and xanthohumol metabolites. Mol Nutr Food Res 2005;49(9):827-31.

10. Evrendilek GA. Empirical prediction and validation of antibacteria inhibitory effects of various plant essential oils on common pathogenic bacteria. Int J Food Microbiol 2015;202:35-41.

11. Bocquet L, Riviere C, Neut C, Mahieu S, Roumy V, Hennebelle T, Bordage S, Samaillie J, Sahpaz S. Antimicrobial properties of phenolic compounds from hops, Humulus lupulus L.: fight against multidrug resistance. Planta Med 2016;82(S 01):S1-S381.

12. Cermak P, Olsovska J, Mikyska A, Dusek M, Kadleckova Z, Vanicek J, Nyc O, Sigler K, Bostikova V, Bostik P. Strong antimicrobial activity of xanthohumol and other derivatives from hops (Humulus lupulus L.) on gut anaerobic bacteria. AMPIS 2017;125:1033-8.

13. Bhattacharya S, Virani S, Zavro M, Haas GJ. Inhibition of Streptococcus mutans and other oral streptococci by hop (Humulus lupulus L.) constituents. Econ Bot 2003;57(1):118-25.

14. Shinada $K$, Tagashira $M$, Watanabe $H$, Sopapornamorn $P$, Kanayama A, Kanda, Ikeda M, Kawaguchi Y. Hop bract polyphenols reduced three-day dental plaque regrowth. J Dent Res 2007;86(9):848-51.

15. Tharakan, S, Lakshmi T. Humulus lupulus in management of orodental pathogens - An update. J Pharm Sci \& Res 2013;5(9):187-9.

16. Pilná J, Vlková E, Krofta K, Nesvadba V, Rada V, Kokoška L. In vitro growth-inhibitory effect of ethanol GRAS plant and supercritical $\mathrm{CO}_{2}$ hop extracts on planktonic cultures of oral pathogenic microorganisms. Fitoterapia 2015;105:260-8.

17. Yamaguchi N, Satoh-Yamaguchi K, Ono M. In vitro evaluation of antibacterial, anticollagenase, and antioxidant activities of hop components (Humulus lupulus) addressing acne vulgaris. Phytomedicine 2009:16(4):369-76.

18. Dumas ER, Michaud AR, Bergeron C, Lafrance J, Mortillo S, Gafner S. Deodorant effects of a supercritical hops extract: antibacterial activity against Corynebacterium xerosis and Staphylococcus epidermidis and efficacy testing of a hops/zinc ricinoleate stick in humans through the sensory evaluation of axillary deodorancy. J Cosmet Dermatol 2009;8(3):197-204.

19. Dušek M, Jandovská V, Čermák P, Mikyška A, Olšovská J. A novel approach for identification of biologically active phenolic compounds in complex matrices using hybrid quadrupole-orbitrap mass spectrometer: A promising tool for testing antimicrobial activity of hops. Talanta 2016;156-157:209-17.

20. European Brewery Convention (EBC). 2010. $\alpha$ - and $\beta$-Acids in Hops and Hop Products by HPLC. Chap. 7.7. In: Analytica EBC. EBC Analysis Commitee-Nürnberg, Carl Getranke-Fachverlag

21. Krofta K, Lišková H, Vrabcová S. Způsob přípravy čistých beta kyselin chmele. 2012. Czech Patent No. 303017, Úřad průmyslového vlastnictví, Praha.

22. European Committee on Antimicrobial Susceptibility Testing. 2016. Antimicrobial Susceptibility Testing of Bacteria. Available at http:// www.eucast.org/ast_of_bacteria.

23. Langezaal CR, Chandra A, Sheffer JJC. Antimicrobial screening of essential oils and extracts of some Humulus lupulus L. cultivars. Pharm Weekbl Sci 1992;14(6):353-6.

24. Rozalski M, Micota B, Sadowska B, Stochmal A, Jedrejek D, Wieckowska-Szakiel M, Rozalska BM. Antiadherent and antibiofilm activity of Humulus lupulus L. derived products: New pharmacological properties. BioMed Res Int 2013 Sep 23; Article ID 101089:7 pages. doi:10.1155/2013/101089

25. Ohsugi $M$, Basnet $P$, Kadota $S$, Ishii E, Tamura T, Okumura $Y$, Namba T. Antibacterial activity of traditional medicines and an active constituent lupulone from Humulus lupulus against Helicobacter pylori. J Trad Med 1997;14:186-91.

26. Matos R, Vasconcelos L, Oleastro M, Monterio L. Antibacterial activity of Humulus lupulus against Helicobacter pylori. Gut 2001;49(4):p A5.

27. Čermák $P$, Palečkova V, Houška $M$, Strohalm J, Novotná P, Mikyška A, Jurková M, Sikorová M. 2015. Inhibitory effects of fresh hops on Helicobacter pylori strains. Czech J Food Sci 2015;33(4):302-7.

28. Kramer B, Thielmann J, Hickisch A, Muranyi P, Wunderlich J, Hauser C. Antimicrobial activity of hop extracts against foodborne pathogens for meat applications. J Appl Microbiol 2015;118(3):648-57.

29. Mizobuchi S, Sato Y. A new flavanone with antifungal activity isolated from hops. Agric Biol Chem 1984;48(11):2771-5.

30. Mizobuchi S, Sato Y. Antifungal activities of hop bitter resins and related compounds. Agric Biol Chem 1985;49(2):399-403. 